\title{
Incidência e representações do uso de drogas lícitas e ilícitas nos câmpus da Universidade Federal de Goiás: desafios para a proposição de uma política
}

\author{
Dijaci David de Oliveira \\ Doutor em Sociologia pela Universidade de Brasília \\ Professor da Universidade Federal de Goiás \\ dijaci@ufg.br \\ Guilherme Borges da Silva \\ Doutorando em Sociologia pela Universidade Federal de Goiás \\ guidhu@gmail.com \\ Michele Cunha Franco \\ Universidade Federal de Goiás \\ mcfrancojur@gmail.com
}

Pós-doutoranda pelo Programa de Pós-Graduação Interdisciplinar em Direitos Humanos pela

\begin{abstract}
Resumo O consumo de substâncias psicoativas lícitas e ilícitas no âmbito das universidades tem sido mapeado tanto no Brasil como em outros países, bem como tem desafiado essas instituições a refletirem acerca da implementação de políticas que não reproduzam os erros da maioria das iniciativas vigentes em esferas públicas mais abrangentes. $\mathrm{O}$ objetivo deste artigo é analisar a incidência e as percepções do uso de drogas lícitas e ilícitas nos câmpus da Universidade Federal de Goiás (UFG), com base em dados coletados nos anos de 2015 e 2016 por meio de três procedimentos: survey, grupos focais e entrevistas em profundidade. Por meio dessa análise, buscaremos contribuir para a reflexão acerca de políticas que possam reduzir os danos que tanto a percepção do consumo quanto o próprio consumo dessas substâncias potencialmente podem causar às comunidades das instituições de ensino superior, o que inclui discutirmos em que medida as prenoções relativas às drogas, sobretudo ilícitas, assim como o uso dessas substâncias podem afetar a qualidade do convívio nessa comunidade.
\end{abstract}

Palavras-chave: substâncias psicoativas, universidades, políticas sobre drogas.

\section{Introdução}

A s representações acerca do uso de substâncias psicoativas estão su-

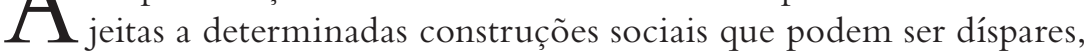
tanto se tomado o aspecto temporal quanto cultural. Ademais, a definição de quais drogas são lícitas ou ilícitas se dá por meio de disputas entre saberes jurídicos e médicos, bem como por interesses políticos e econômicos e está, ainda, sujeita a intersecções relativas a classe, gênero e raça (Coyle, 2003; Cruz; Machado; Fernandes, 2012; Linnemann, 2008). As tentativas de controle ou até mesmo de erradicação do uso dessas substâncias passou a se intensificar a partir do século XIX, quando 
o paradigma proibicionista foi adotado e se espraiou pelo mundo ocidental, sobretudo a partir da década de 1960, quando se firmou a "Convenção Única sobre Entorpecentes,"1 que ratificou as premissas da "Convenção do Ópio", que fora firmada em Haia no ano de 1912 (Fiore, 2012; Machado; Boarini, 2013).

Nesse campo de disputas, estabeleceram-se quais substâncias, dentre as capazes de alterar a percepção e consciência humanas, seriam toleradas, ou mesmo incentivadas - como é o caso da excessiva prescrição de psicotrópicos, sobretudo ansiolíticos e antidepressivos, por médicos (Pelegrini, 2003) -, e quais deveriam ser combatidas. Essa definição influenciou o imaginário social, que passou a considerar como drogas, sobretudo, aquelas substâncias consideradas ilegais e, excepcionalmente, o álcool e o tabaco. Não é tema deste artigo discutir qual deveria ser o status das substâncias psicoativas, mas não podemos deixar de apontar que a categoria droga, sob o ponto de vista sociológico, é uma categoria multifacetada e complexa dentro de uma disputa do campo de saber/poder que envolve tanto o jurídico, o político quanto o médico, a moral, o religioso, além de expressivos interesses econômicos - seja da indústria farmacêutica, seja de grupos que lucram com a ilegalidade desse mercado. É importante, entretanto, evidenciar nossa compreensão de que, além de ser intrínseco à cultura humana, o fenômeno das drogas está sujeito às dinâmicas advindas de parâmetros morais, religiosos e científicos que, assim como as culturas, são passíveis de alterações no tempo e no espaço.

Predomina o paradigma proibicionista e é com base nele que se constroem as percepções - não raro enviesadas, $^{2}$ - sobre essas substâncias, reforçadas pelos olhares midiático e policial. Fruto disso, aponta Carneiro (2002, p. 13), é o fato de que em nossa sociedade "nenhum personagem sintetiza melhor a paranoia pública da nossa era do que o do viciado e do traficante". Como destaca o autor, esses personagens são demonizados, e isso nos remete imediatamente às figuras do "bode expiatório", isto é, também sobre elas recaíram parte expressiva das culpas pelos problemas sociais vivenciados pela sociedade (Girard, 2004, 2008).

Desse contexto, decorre a equivocada associação de que o uso de substâncias psicoativas ilegais é por si um elemento fomentador da violência. Essa hipótese foi refutada por vários autores (Goldstein, 1985; Shecaira, 2014; Torquato, 2016; Zaluar, 2002). Goldstein (1985) analisou a existência desse suposto nexo com base em três hipóteses: a psicofarmacológica; a da compulsão pelo uso e consequente necessidade de satisfação a essa compulsão; e, por último, a que chamou de nexo sistêmico, ou seja, decorrente da própria lógica de um mercado ilegal, em que as pendências são resolvidas por meio da violência. ${ }^{3} \mathrm{O}$ autor aponta que há relação entre o consumo de drogas e a violência, porém nada significativo quando comparado à violência sistêmica que deriva desse mercado criminalizado, que diz respeito aos atos delituosos e violentos cometidos no seu contexto de funcionamento, das atividades de venda e distribuição.

Uma associação frequente, tema central deste artigo, é feita entre consumo de substâncias psicoativas e juventude, como componente de uma cultura hedonista, ou por "pressão do grupo" que levaria, ao consumo, jovens que buscam alcançar pertencimento a um grupo e/ou estilo de vida, embora existam estudos que apontem que a drogadição entre a população idosa tem sido um problema negligenciado pelas políticas de saúde (Roe et al, 2010; Taylor; Grossberg, 2012). Quando falamos sobre a juventude universitária, essa representação ganha vigor, uma vez que há levantamentos que corroboram que é na faixa etária entre 18 e 24 anos que prevalece o uso de drogas consideradas ilícitas.

Nos Estados Unidos, de acordo com dados obtidos pelo Center for Behavioral Health Statistics and Quality (Center, 2015), os percentuais de pessoas que haviam usado drogas ilícitas no ano de 2014 - ao menos no mês anterior ao survey - era de $9,4 \%$ na faixa etária de 12 a 17 anos, 22\% entre 18 e 25 anos e de $8,3 \%$ na faixa de 26 anos ou mais. Quando se faz a mesma pergunta, mas se restringindo ao uso de maconha no último mês, esses percentuais são, respectivamente, de $7,4 \% ; 19,6 \%$ e $6,6 \%$.

Quanto às demais drogas pesquisadas: cocaína, heroína, estimulantes, metanfetamina, inalantes e as que estão na classe de alucinógenos (LSD, Peyote, PCP, Mescalina, Ecstasy, Cogumelos), o consumo no mês anterior à pesquisa atingiu um dígito apenas na faixa etária de 18 a 25 anos, e somente para o consumo de cocaína, em 1,4\%, estimulantes, em 1,2\% e todas as alucinógenas juntas, com 1,4\%. Do que se percebe uma grande concentração de uso de maconha em relação às demais.

O Centro Brasileiro de Informações sobre Drogas (Cebrid), da Universidade Federal de São Paulo (Unifesp), em levantamento domiciliar feito em 2005, chegou a conclusões semelhantes, exceto

1. A Convenção foi aprovada em 1961. No Brasil, foi transformada em lei por meio do Decreto nº 54.216, de 27 de agosto de 1964 (Senado Federal, 2015).

2. Pode-se afirmar isso pela percepção que se tem de que muitas drogas, por atenderem aos interesses políticos, culturais ou econômicos, sequer são apontadas como drogas e são abertamente utilizadas, como por exemplo, o álcool (Lemgruber; Boiteaux, 2014; Torcato, 2016).

3. Mercados ilegais, como a extração de madeira, jogo do bicho, carvoaria, tráfico de armas, exploração de profissionais do sexo, são fundados em práticas violentas. 
na faixa etária de entrada - 12 a 17 anos -, pois o consumo nos EUA é significativamente maior que aqui: usuários de maconha na faixa etária de 12 a 17 eram da ordem de 4,1\%, já entre 18 e 24 anos, eram $17 \%$ e entre 25 e 35 anos, $5,6 \%{ }^{4}$ (Cebrid, 2006).

A análise que segue, acerca dos dados obtidos na pesquisa realizada entre 2015 e 2016 nos câmpus da Universidade Federal de Goiás (UFG), leva em consideração que a definição acerca da legalidade ou ilegalidade de substâncias psicoativas e da pertinência do seu uso decorre de disputas que se operam no campo moral, religioso, ${ }^{5}$ cultural, comercial, científico, jurídico e político. Por conseguinte, as representações sociais acerca do uso dessas substâncias sofrerão influências das percepções expostas pelos meios de comunicação e instituições como igreja, escola, polícia, o que torna problemática a assunção do consumo por parte de pessoas usuárias. Isso porque tais práticas são tomadas como inadequadas por grande parte da população, além de serem reprimidas pelo Estado, embora acompanhem a humanidade em sua história.

\section{Metodologia}

Este trabalho decorre da pesquisa "Violências, conflitos e crimes: subsídios para a formulação da política de segurança da Universidade Federal de Goiás" realizada pelo Núcleo de Estudos sobre Criminalidade e Violência (Necrivi/UFG). Iniciada no segundo semestre de 2014, a pesquisa teve como um de seus objetivos, identificar as representações, os valores e as práticas da comunidade universitária sobre violência, conflitos e crimes nas quatro Regionais da Universidade Federal de Goiás (situadas nas cidades de Goiânia, ${ }^{6}$ Catalão, Jataí e Cidade de Goiás). Para tanto, três estratégias metodológicas de caráter qualitativo e quantitativo foram adotadas visando à obtenção dos dados entre docentes, discentes, servidores técnico-administrativos e funcionários terceirizados: a) entrevistas em profundidade, b) grupos focais e c) survey.

Com relação ao primeiro recurso metodológico, foram realizadas 51 entrevistas em profundidade, mediante a seleção de professores e alunos das oito gran- des áreas do conhecimento disponibilizadas pela UFG, ou seja, de cursos de graduação em Ciências Agrárias, Biológicas, da Saúde, Exatas, Humanas, Sociais Aplicadas, da Terra, e ainda, Engenharias, Linguística, Letras e Artes. Além desses, foram entrevistados servidores técnico-administrativos, alguns escolhidos conforme sua atuação profissional em pesquisas e/ou em movimentos sociais ou estudantis, relacionados ao debate de temas como: violências; consumo e tráfico de drogas; educação intercultural; ações afirmativas; identidades de gênero; políticas estudantis e LGBT; atividades esportivas; comunicação, segurança e saúde universitárias.

Para a construção da rede social dos sujeitos da pesquisa foi utilizada a técnica do snowball -'bola de neve'- (Bernard, 1988), estratégia para coleta de dados que consiste, primeiramente, na localização dos indivíduos-chave para o desenvolvimento da pesquisa e, posteriormente, na solicitação para que eles nomeiem outras pessoas que possam contribuir para a temática em análise. As entrevistas foram pessoais, semiestruturadas em perguntas e tópicos para discussão, os quais foram elaborados mediante roteiro embasado na bibliografia e nos objetivos da pesquisa, e registradas com o auxílio de gravadores digitais e celulares.

Já com relação à segunda estratégia metodológica, foram realizados 13 grupos focais, sendo esses apenas com alunos de graduação das mais diversas áreas do conhecimento e em todos os câmpus da UFG. ${ }^{7}$ Essa técnica, segundo Minayo (2008), se constitui em um tipo de entrevista ou conversa em grupos formados com base na homogeneidade em alguns fatores, e não necessariamente em todos, como sexo, idade, classe social, nível educacional, tipo de cultura, entre outros, a fim de se criar uma interação semelhante àquela que se verifica na vida social. Conforme Borges e Santos (2005), é aconselhado, entretanto, que os participantes não tenham laços entre si, a fim de evitar que haja receio de julgamentos recíprocos relativos às opiniões manifestadas.

Para que o moderador possa cumprir a contento o seu papel, a construção do roteiro é importante, o qual deve apresentar duas características fundamentais: ser "provocador para permitir um debate entusiasmado e participativo e promover condições de aprofundamento, fazendo jus ao que se pretende com esta técnica"

4. No caso de uso de cocaína, prevaleciam usuários na faixa de 25 a 34 anos, com 5,2\%, já entre 18 e 24 anos seriam 4,2\%.

5. Em 2010, o Conselho Nacional de Políticas sobre Drogas (Conad), deliberou a respeito do uso, para fins religiosos, do chá conhecido como Ayahuasca, embora em sua composição haja substância psicoativa proscrita.

6. A UFG possui três Câmpus na capital Goiânia: o Câmpus Samambaia, no norte da cidade; o Câmpus Colemar Natal e Silva, no leste, o mais antigo; e o Câmpus de Aparecida de Goiânia - município conurbado à capital -, o mais recente. Dado o contexto multicâmpus, a UFG considera os três como uma única regional.

7. Os Grupos focais foram realizados no Câmpus Samambaia (dois) e no Câmpus Colemar Natal e Silva (dois), totalizando quatro em Goiânia. Além desses, mais três em cada uma das Regionais situadas em Catalão, Jataí e Cidade de Goiás. 
(Minayo, 2008, p. 192-193). São também relevantes o ambiente, livre de estímulos visuais e auditivos, ou ruídos e interrupções externas, a fim de evitar a dispersão dos participantes (Ashidamini; Saupe, 2004; Trad, 2009), e o moderador, que não deve ser diretivo, o que significa que os participantes possam falar sem a indução de perguntas muito específicas e ainda possam trocar impressões entre si. Caberá também ao moderador promover a participação e o ponto de vista de todos e cada um, além de impedir a dispersão dos temas e a monopolização por um dos participantes, atuando, porquanto, como um facilitador e não como alguém que possa direcionar, inibir ou cercear opiniões. $\mathrm{Na}$ pesquisa em foco, os grupos tiveram duração média de uma hora e o instrumento utilizado para coletar as informações, posteriormente transcritas, foi gravador digital.

Tanto o roteiro das entrevistas em profundidade quanto o dos grupos focais trouxeram à tona diferentes discursos da comunidade universitária da UFG com relação a temas como: a) criminalidades e violências materiais ou simbólicas - étnico-racial, homofóbica, lesbiofóbica, transfóbica, sexista, dentre outras no âmbito da UFG e criminalidades nos bairros vizinhos; b) utilização dos espaços na UFG pela comunidade interna e em geral, e sentimento de (in)segurança nesses espaços; c) medidas de segurança que deveriam ser adotadas e temas subjacentes como a presença da Polícia Militar nos câmpus, segurança privada e equipamentos de vigilância.

Dentre os tópicos propostos, interessa a esta análise o que diz respeito ao consumo e ao tráfico de drogas na UFG. Neste, foram feitas as seguintes perguntas: o que você pensa sobre o uso de drogas na comunidade universitária? O uso de drogas atrai a criminalidade para dentro da UFG? Já presenciou, ou ouviu falar, de espaços da UFG onde há consumo de álcool e outras drogas? Se sim, quais? Quais as medidas que a UFG poderia tomar com relação à questão das drogas?

Por fim, a terceira estratégia metodológica, o survey, abrangeu a comunidade universitária. Para a construção da amostra levou-se em consideração, além das
Regionais, as categorias de pertencimento à Universidade. A comunidade da UFG é composta da seguinte forma:

Com o intuito de preservar tais estratos e suas respectivas características, construiu-se uma amostra a partir da retirada de amostras em proporções convenientes de cada um dos estratos que dividem a população. Essas proporções foram definidas com base nos 'pesos' que cada estrato possui em relação ao universo. Pode-se observar que cada Regional tem um peso relativo à população e que, dentro de cada Regional, cada categoria possui um peso relativo àquele primeiro estrato pertencente. Esses pesos foram utilizados no desenho da amostra, o que permitiu que a sua alocação ocorresse de forma proporcional, segundo o desenho da população. Uma vez definida a distribuição da amostra, a retirada dos elementos ocorreu segundo um processo de amostragem aleatória simples.

Portanto, calculou-se o tamanho da amostra a partir da observação da proporção populacional, P, de uma amostragem aleatória simples sem reposição. Admitindo um erro amostral, $\epsilon=3 \%$ e um nível de confiança, $\alpha=5 \%$, e, ainda, assumindo um valor de $\mathrm{P}=1 / 2$, o tamanho de amostra encontrado é $n=1.028$. Sabe-se que os casos de não resposta podem chegar a $20 \%$ do total da amostra, o que levou à decisão de incluir mais $20 \%$ de "n" na seleção, do que resultou um número total de 1.234 pessoas amostradas.

O campo foi realizado nas quatro regionais da UFG (Goiânia, Jataí, Catalão e Cidade de Goiás). Por seguir o modelo probabilístico por meio do sorteio dos participantes, houve a necessidade de agendar as entrevistas por meio de telefonemas, e-mails ou pessoalmente. Concomitantemente, foram aplicados os questionários assim como o seu processo de codificação e tabulação. Esse processo se deu por meio da utilização do software Statistical Package for the Social Sciences (SPSS), o qual também foi utilizado para produzir as tabelas que se encontram neste artigo.

Tabela 1 - Alocação da população por Regional e categorias

\begin{tabular}{|c|c|c|c|c|c|c|c|c|}
\hline Regional & \multicolumn{2}{|c|}{ Catalão } & \multicolumn{2}{|c|}{ Goiás } & \multicolumn{2}{|c|}{ Goiânia } & \multicolumn{2}{|c|}{ Jataí } \\
\hline Categoria & $\mathrm{F}^{(1)}$ & $\mathrm{Fr}{ }^{(2)}$ & F & $\mathrm{Fr}$ & $\mathrm{F}$ & $\mathrm{Fr}$ & F & $\mathrm{Fr}$ \\
\hline Docente & 294 & 0.091 & 77 & 0.098 & 1.959 & 0.094 & 329 & 0.102 \\
\hline Servidor & 71 & 0.022 & 19 & 0.024 & 2.228 & 0.106 & 77 & 0.024 \\
\hline Terceirizado & 132 & 0.041 & 8 & 0.010 & 1.289 & 0.062 & 198 & 0.061 \\
\hline Aluno & 2.751 & 0.847 & 679 & 0.867 & 15.471 & 0.739 & 2.626 & 0.813 \\
\hline Total & 3.248 & 1 & 783 & 1 & 20.947 & 1 & 3.230 & 1 \\
\hline
\end{tabular}

Fonte: Sistema de Referências - Pesquisa Violências, Conflitos e Crimes - UFG, 2015/2016.

Nota: (1) frequência absoluta; (2) frequência relativa (percentual). 


\section{Resultados}

A apresentação dos resultados será focada em dois pontos: as percepções sobre o consumo de drogas e a incidência do consumo. $\mathrm{O}$ primeiro pon- to terá como base as entrevistas em profundidade cotejadas com os dados obtidos no grupo focal e, como pano de fundo, as respostas obtidas no survey (Tabelas 2, 3 e 4). Já o segundo, tomará o survey, em específico os dados do consumo entre os alunos.

Tabela 2 - Frequência que fica sabendo sobre ocorrência de consumo de drogas ilícitas

\begin{tabular}{|c|c|c|c|c|c|c|}
\hline \multirow{14}{*}{$\begin{array}{l}\text { Frequência que você fica } \\
\text { sabendo sobre consumo de } \\
\text { drogas ilícitas na UFG }\end{array}$} & \multirow{2}{*}{\multicolumn{2}{|c|}{ UFG }} & \multicolumn{4}{|c|}{ Categoria } \\
\hline & & & \multirow{2}{*}{$\begin{array}{c}\text { Professor(a) } \\
15\end{array}$} & \multirow{2}{*}{$\frac{\text { Técnico(a) }}{9}$} & \multirow{2}{*}{$\frac{\text { Terceirizado(a) }}{14}$} & \multirow{2}{*}{$\frac{\text { Aluno(a) }}{166}$} \\
\hline & \multirow{3}{*}{ Não acontece } & 204 & & & & \\
\hline & & $30,50 \%(1)$ & $28,30 \%$ & $17,30 \%$ & $37,80 \%$ & $31,50 \%$ \\
\hline & & $30,50 \%$ & $2,20 \%$ & $1,30 \%$ & $2,10 \%$ & $24,80 \%$ \\
\hline & \multirow{3}{*}{$\begin{array}{l}\text { Acontece } \\
\text { raramente }\end{array}$} & 137 & 9 & 9 & 3 & 116 \\
\hline & & $20,50 \%$ & $17,00 \%$ & $17,30 \%$ & $8,10 \%$ & $22,00 \%$ \\
\hline & & $20,50 \%$ & $1,30 \%$ & $1,30 \%$ & $0,40 \%$ & $17,30 \%$ \\
\hline & \multirow{3}{*}{$\begin{array}{l}\text { Acontece } \\
\text { frequentemente }\end{array}$} & 305 & 23 & 30 & 19 & 233 \\
\hline & & $45,60 \%$ & $43,40 \%$ & $57,70 \%$ & $51,40 \%$ & $44,20 \%$ \\
\hline & & $45,60 \%$ & $3,40 \%$ & $4,50 \%$ & $2,80 \%$ & $34,80 \%$ \\
\hline & \multirow{3}{*}{ NSD/NR } & 23 & 6 & 4 & 1 & 12 \\
\hline & & $3,40 \%$ & $11,30 \%$ & $7,70 \%$ & $2,70 \%$ & $2,30 \%$ \\
\hline & & $3,40 \%$ & $0,90 \%$ & $0,60 \%$ & $0,10 \%$ & $1,80 \%$ \\
\hline \multirow{3}{*}{\multicolumn{2}{|c|}{ Total }} & 669 & 53 & 52 & 37 & 527 \\
\hline & & $100,00 \%$ & $100,00 \%$ & $100,00 \%$ & $100,00 \%$ & $100,00 \%$ \\
\hline & & $100,00 \%$ & $7,90 \%$ & $7,80 \%$ & $5,50 \%$ & $78,80 \%$ \\
\hline
\end{tabular}

Fonte: Violências, conflitos e crimes: subsídios para a formulação da política de segurança da UFG.

Nota: (1) total de entrevistados na UFG que responderam "não acontece"; (2) total de professores na UFG que responderam "não acontece"; ${ }^{3)}$ professores que responderam "não acontece" em relação à população total entrevistada.

Tabela 3 - As pessoas da UFG consomem muitas drogas

\begin{tabular}{|c|c|c|c|c|c|c|}
\hline \multirow{20}{*}{$\begin{array}{l}\text { As pessoas da UFG } \\
\text { consomem muitas } \\
\text { drogas }\end{array}$} & \multirow{2}{*}{\multicolumn{2}{|c|}{ UFG }} & \multicolumn{4}{|c|}{ Categoria } \\
\hline & & & \multirow{2}{*}{$\begin{array}{c}\text { Professor(a) } \\
12\end{array}$} & \multirow{2}{*}{$\begin{array}{c}\text { Técnico(a) } \\
15 \\
\end{array}$} & \multirow{2}{*}{$\begin{array}{c}\text { Terceirizado(a) } \\
14\end{array}$} & \multirow{2}{*}{$\begin{array}{c}\text { Aluno(a) } \\
141\end{array}$} \\
\hline & \multirow{3}{*}{$\begin{array}{l}\text { Concordo } \\
\text { totalmente }\end{array}$} & 182 & & & & \\
\hline & & $27,20 \%^{(1)}$ & $22,60 \%(2)$ & $28,80 \%$ & $37,80 \%$ & $26,80 \%$ \\
\hline & & $27,20 \%$ & $1,80 \%{ }^{(3)}$ & $2,20 \%$ & $2,10 \%$ & $21,10 \%$ \\
\hline & \multirow{3}{*}{$\begin{array}{l}\text { Concordo em } \\
\text { parte }\end{array}$} & 232 & 17 & 17 & 6 & 192 \\
\hline & & $34,70 \%$ & $32,10 \%$ & $32,70 \%$ & $16,20 \%$ & $36,40 \%$ \\
\hline & & $34,70 \%$ & $2,50 \%$ & $2,50 \%$ & $0,90 \%$ & $28,70 \%$ \\
\hline & \multirow{3}{*}{$\begin{array}{l}\text { Nem concordo e } \\
\text { nem discordo }\end{array}$} & 61 & 10 & 5 & 5 & 41 \\
\hline & & $9,10 \%$ & $18,90 \%$ & $9,60 \%$ & $13,50 \%$ & $7,80 \%$ \\
\hline & & $9,10 \%$ & $1,50 \%$ & $0,70 \%$ & $0,70 \%$ & $6,10 \%$ \\
\hline & \multirow{3}{*}{$\begin{array}{l}\text { Discordo em } \\
\text { parte }\end{array}$} & 91 & 4 & 9 & 3 & 75 \\
\hline & & $13,60 \%$ & $7,50 \%$ & $17,30 \%$ & $8,10 \%$ & $14,20 \%$ \\
\hline & & $13,60 \%$ & $0,60 \%$ & $1,30 \%$ & $0,40 \%$ & $11,20 \%$ \\
\hline & \multirow{3}{*}{$\begin{array}{l}\text { Discordo } \\
\text { totalmente }\end{array}$} & 101 & 9 & 6 & 9 & 77 \\
\hline & & $15,10 \%$ & $17,00 \%$ & $11,50 \%$ & $24,30 \%$ & $14,60 \%$ \\
\hline & & $15,10 \%$ & $1,30 \%$ & $0,90 \%$ & $1,30 \%$ & $11,50 \%$ \\
\hline & \multirow{3}{*}{ NSD/NR } & 2 & 1 & 0 & 0 & 1 \\
\hline & & $0,30 \%$ & $1,90 \%$ & $0,00 \%$ & $0,00 \%$ & $0,20 \%$ \\
\hline & & $0,30 \%$ & $0,10 \%$ & $0,00 \%$ & $0,00 \%$ & $0,10 \%$ \\
\hline \multirow{3}{*}{\multicolumn{2}{|c|}{ Total }} & 669 & 53 & 52 & 37 & 527 \\
\hline & & $100,00 \%$ & $100,00 \%$ & $100,00 \%$ & $100,00 \%$ & $100,00 \%$ \\
\hline & & $100,00 \%$ & $7,90 \%$ & $7,80 \%$ & $5,50 \%$ & $78,80 \%$ \\
\hline
\end{tabular}

Fonte: Violências, conflitos e crimes: subsídios para a formulação da política de segurança da UFG.

Nota: ${ }^{(1)}$ entrevistados na UFG que responderam "concordo totalmente"; ${ }^{(2)}$ total de professores na UFG que responderam "concordo totalmente"; (3) professores que responderam "concordo totalmente" em relação à população total entrevistada. 
Tabela 4 - Você é a favor da legalização da maconha?

\begin{tabular}{|c|c|c|c|c|c|c|}
\hline \multirow{11}{*}{$\begin{array}{l}\text { Você é a favor } \\
\text { da legalização da } \\
\text { maconha? }\end{array}$} & \multirow{2}{*}{\multicolumn{2}{|c|}{ UFG }} & \multicolumn{4}{|c|}{ Categoria } \\
\hline & & & \multirow{2}{*}{$\begin{array}{c}\text { Professor(a) } \\
20\end{array}$} & \multirow{2}{*}{$\begin{array}{c}\text { Técnico(a) } \\
13 \\
\end{array}$} & \multirow{2}{*}{$\begin{array}{c}\text { Terceirizado(a) } \\
7\end{array}$} & \multirow{2}{*}{$\begin{array}{c}\text { Aluno(a) } \\
148\end{array}$} \\
\hline & \multirow{3}{*}{ Sim } & 188 & & & & \\
\hline & & $28,10 \%{ }^{(1)}$ & $37,70 \%$ & $25,00 \%$ & $18,90 \%$ & $28,10 \%$ \\
\hline & & $28,10 \%$ & $3,00 \%$ & $1,90 \%$ & $1,00 \%$ & $22,10 \%$ \\
\hline & \multirow{3}{*}{ Não } & 431 & 29 & 32 & 28 & 342 \\
\hline & & $64,40 \%$ & $54,70 \%$ & $61,50 \%$ & $75,70 \%$ & $64,90 \%$ \\
\hline & & $64,40 \%$ & $4,30 \%$ & $4,80 \%$ & $4,20 \%$ & $51,10 \%$ \\
\hline & \multirow{3}{*}{ NSD/NR } & 50 & 4 & 7 & 2 & 37 \\
\hline & & $7,50 \%$ & $7,50 \%$ & $13,50 \%$ & $5,40 \%$ & $7,00 \%$ \\
\hline & & $7,50 \%$ & $0,60 \%$ & $1,00 \%$ & $0,30 \%$ & $5,50 \%$ \\
\hline \multirow{3}{*}{ Total } & & 669 & 53 & 52 & 37 & 527 \\
\hline & & $100,00 \%$ & $100,00 \%$ & $100,00 \%$ & $100,00 \%$ & $100,00 \%$ \\
\hline & & $100,00 \%$ & $7,90 \%$ & $7,80 \%$ & $5,50 \%$ & $78,80 \%$ \\
\hline
\end{tabular}

Fonte: Violências, conflitos e crimes: subsídios para a formulação da política de segurança da UFG.

Nota: ${ }^{(1)}$ total de entrevistados na UFG que responderam "sim"; ${ }^{(2)}$ total de professores na UFG que responderam "sim"; ${ }^{(3)}$ professores que responderam "sim" em relação à população total entrevistada.

\section{As percepções sobre o consumo de drogas}

Dentre os quatro segmentos (professores, técnicos, terceirizados e estudantes) questionados sobre a percepção do consumo de drogas ilícitas nos câmpus da UFG, observou-se predominância nas respostas dos técnico-administrativos (57,7\%), seguidos pelos terceirizados $(51,4 \%)$, para os quais há consumo frequente de drogas. Esses percentuais ficam acima da média, que é de $(45,6 \%)$ dos respondentes, se incluídas as demais categorias - professores e alunos. $\mathrm{E}$, para $51 \%$ dos que responderam, o consumo não acontece ou ocorre raramente.

Uma segunda questão foi proposta para que se verificasse a intensidade da percepção do consumo. Assim, questionados se as pessoas da UFG consomem muitas drogas, $27,2 \%$ afirmaram que concordam totalmente. Entre os técnicos, o percentual foi de $28,8 \%$ e entre os terceirizados foi de $37,8 \%$. O maior percentual de discordância (discorda totalmente) foi entre os terceirizados, $24,3 \%$, seguidos pelos docentes, $17 \%$ do total.

Tendo em vista que no centro da discussão sobre políticas de drogas está a dicotomia descriminalização/proibição, questionou-se o grau de aceitação de políticas no sentido de legalizar o uso da maconha. Responderam negativamente $64,4 \%$ dos entrevistados, entre os terceirizados esse índice chega a $75,7 \%$. O maior percentual de aceitação foi entre os docentes com $37,7 \%$, seguidos pelos estudantes, com $28,1 \%$.

É possível perceber uma forte resistência, sobretudo entre os terceirizados, com relação às políticas de legalização. É o mesmo segmento que afirma de forma mais contundente que há um forte consumo de drogas dentro dos câmpus. A percepção dos terceirizados com relação ao consumo de drogas no espaço universitário se deve, sobretudo, por estarem alocados em espaços mais abertos, fora de gabinetes, e muitas vezes circulando dentro dos prédios ou, no caso da vigilância contratada, por todo território da universidade. Evidentemente, quanto mais circulam, maior a probabilidade de depararem com pessoas consumindo, ainda mais quando a função exercida, no caso dos vigilantes, exige um olhar cuidadoso sobre comportamentos tidos como desviantes.

\section{Entrevistas em profundidade}

As entrevistas em profundidade objetivaram buscar mais dados sobre a percepção do consumo de drogas, mas sobretudo compreender se e em que medida as práticas de uso, venda e consumo de drogas representam um problema, uma ameaça para a comunidade universitária e, em especial, o que se espera dos gestores. Essa parte está estruturada em três tópicos: o primeiro voltado à percepção de consumo e da venda de substâncias psicoativas nos câmpus; o segundo ao conhecimento sobre programas e iniciativas sobre como lidar com o tema "dro- 
gas"; e, por fim, quanto à percepção do Programa Saudavelmente. ${ }^{8}$

\section{a) Sobre a percepção de consumo e venda de substâncias psicoativas:}

A leitura das narrativas evidencia uma forte percepção de que existe consumo de drogas (lícitas e ilícitas) dentro dos câmpus da UFG e, ainda, permite afirmar que há uma percepção de que o uso de drogas está se tornando mais ostensivo. Isto é, mais rotineiro, mais intenso e mais visível, sobretudo de álcool e maconha:

Professora \#7: Nosso estudante chega hoje aqui com 16, 17 anos, né? E ele vem já de um universo de consumo de álcool. De álcool destilado, não tô falando da cerveja. Tô falando da vodca, tô falando da cachaça. [...] Antigamente se fumava para agregar ao grupo, agora se bebe para agregar. [...] Então esse é o perfil do estudante que tá chegando.

Professora \#7: [...] Nós temos alunos que estão saindo e estão tendo problemas graves com o álcool, de alcoolismo. Eu tô falando de alcoolismo!

Professor \#2: Lá naquele lugar o "maconhódromo", naquele bosque que o pessoal fuma maconha o dia inteiro. Lá tem o "maconhódromo e sexódromo" que é a matinha. Pra mim tinha que fechar aquilo ali e colocar e botar polícia lá.

Aluna \#6: [...] DCE (Diretório Central dos Estudantes) aí é um antro de drogas. Por isso eu acho que o reitor deveria tomar várias medidas em relação ao DCE. Pra mim a pior droga é o álcool, menor de idade entra aí, bebe e faz o que quiser, eu acho que o DCE é pior do que o bosque (Bosque Auguste de Saint-Hilaire) tendo em vista que eu considero o álcool a pior droga, pior do que a maconha. O DCE ganha em primeiro lugar no quesito drogas (Aluna \#6, 26 anos, Goiânia).

Outro dado importante que podemos extrair das narrativas é que ocorreu uma mudança significativa na entrada de drogas ilícitas na universidade. Se antes ela era trazida pelos estudantes, agora o tráfico se instalou nos câmpus. Soma-se a isso a percepção de que o ambiente universitário está se tornando mais perigoso. Vejamos o que apontam algumas falas:
Professora \#12: [...] Na volta a gente conversando eu falei: mostra esse caminho por dentro da matinha (Bosque Auguste de Saint-Hilaire) que eu quero conhecer como faz encurtar. Ele falou: Professora, vamos pelo caminho normal mesmo. Eu falei: por quê? Ele disse: vou ter que contar pra senhora, mas aqui dentro da mata agora tem tráfico. Os traficantes estão aí.

Aluno \#9: [...] o estudante ele é livre pra fazer o que quer, mas ele tem que ter responsabilidade e o que eu penso sobre essa responsabilidade, você está em um ambiente que é publico, que é aberto e tal, que é a universidade. Mas a gente não pode colocar pessoas em risco [...] não pode ser permitido o comércio aqui dentro [...] (Aluno \#9, 27 anos, Goiânia).

Técnica-administrativa \#4: [...] antes o consumo dentro da universidade era "prioritariamente" da comunidade universitária. Hoje a gente vê elementos externos, que inclusive estão trazendo o tráfico aqui pra dentro. Eu tive conhecimento de que um homem saiu armado do bosque e foi atrás de um técnico, ou aluno, no Instituto de Química (Técnica-administrativa \#4, idade não identificada, Goiânia).

Professora \#27: [...] eu penso que se dentro da universidade a gente conseguir fazer alguma coisa com relação à droga, isso pode estender aqui pra fora.

Aluna \#6: [...] a polícia não pode entrar lá, então eles vão pra lá, porque acham que vão poder fazer o que quiser, lá não tem segurança mesmo, então vamos fazer de lá a casa da mãe Joana. Eu acho que é isso!

Professor \#15: Para consumir droga tem que se relacionar com bandido, pelo princípio da coisa já não é legal. Antigamente [...] Quem era usuário, trazia suas drogas... Agora, a UFG está virando um ponto de drogas. (Professor \#15, 52 anos, Goiânia).

A entrada do tráfico nos câmpus, em especial no Câmpus Samambaia, ocorreu a partir de um conjunto de variáveis. Uma delas está no contexto da repressão violenta contra a venda de drogas no estado de Goiás. Os bairros que margeiam a UFG são bairros populares e com histórico de repressão violenta por parte da

8. Programa Saudavelmente: A Equipe de Saúde Mental do Programa atua no atendimento social, psiquiátrico e psicológico de estudantes e trabalhadores da UFG. Buscando uma compreensão da saúde mental como um processo complexo em que intervêm diversos aspectos, a equipe tem realizado um trabalho amplo, com ações diversificadas, como atendimentos individuais e em grupo, visitas a locais de trabalho, de estudo e domiciliares, reuniões entre profissionais de diferentes áreas e discussões interdisciplinares dos casos. Informações obtidas em: <http://www. saudavelmente.procom.ufg.br/p/1062-apresentacaos 
polícia. Existem pelo menos duas fortes probabilidades para que o tráfico tenha se instalado no Câmpus: ou foi "empurrado" pela ação violenta da polícia, ou foi levado pelos próprios membros da comunidade, sobretudo os estudantes. Uma não necessariamente exclui a outra. O certo é que o fornecimento que antes era feito informalmente por pessoas vinculadas à comunidade universitária (estudantes ou servidores) agora é feito de forma relativamente organizada e hierarquizada, nos moldes da estrutura do tráfico. Isso implica também a possibilidade de recurso à violência como forma de acertos de contas entre credores e devedores. Houve mais de um relato sobre a presença de pessoas armadas nas áreas em que ocorrem com maior frequência a venda e o consumo de drogas ilícitas. Todavia, os dados de ocorrência criminal ainda não apontam casos de violência fatal ou de violência física vinculados ao tráfico.

\section{b) Sobre programas/ iniciativas/ diálogos para} lidar com o tema "drogas":

Para boa parte dos entrevistados, cabe à UFG enfrentar o problema. Seja criando mecanismos para coibir o consumo, seja estudando e ampliando o esclarecimento:

Professora \#7: [...] Falta trazer essa questão pra dentro das Unidades Acadêmicas, eu acho que falta ouvir os estudantes, usuários que tão lá na matinha (Bosque Auguste de Saint-Hilaire) todo dia, duas horas da tarde fumando seu back ${ }^{9}$ depois do almoço. Falta, falta mesmo! E eu tô falando ouvir, não é ouvir pra discriminar não, é ouvir no sentido assim... Eles também se sentem agredidos e vulneráveis (Professora \#7, 34 anos, Goiânia).

Professora \#22: Bom eu acho que caso, como nós temos várias Unidades Acadêmicas que tratam, como a Faculdade de Medicina, Enfermagem e em Faculdades de Ciências Humanas, que poderiam fazer um trabalho integrado com maior questionamento, poderiam tentar identificar os grupos de usuários e tentar fazer um trabalho com eles, seria um papel social da universidade (Professora \#22, 53 anos, Goiânia).

Embora haja o reconhecimento de que o problema é amplo, é social e possui raízes que extrapolam os limites da universidade, ponderam que, ainda assim, cabe à instituição dar uma contribuição para a reflexão sobre o fenômeno:

Funcionário Terceirizado \#3: Debater, conversar. O problema é social, o problema não é da
UFG, a UFG tem que ajudar a resolver como instituição pública que forma pessoas. [...] O problema das drogas é um problema de uma esfera superior que não cabe a UFG resolver, se ela puder resolver é ótimo, mas acredito que ela não vai poder (Funcionário Terceirizado \#3, 30 anos, Jataí).

Professora \#12: Faz parte, o álcool é um elemento de socialização, as pessoas começam a beber muito cedo, então nós temos mensagem muito ambígua em relação às drogas a gente não fala do prazer, a gente não fala que a droga abre o ego, tira a censura e as pessoas se sentem encorajadas, então nós não podemos falar de drogas como se a droga fosse uma droga ruim (Professora \#12, 52 anos, Goiânia).

Assim como na sociedade mais ampla, as preocupações tendem a focalizar mais a questão da segurança e menos as razões e o sentido do uso das drogas. São recorrentes os discursos sobre o medo e a violência. Mas há também narrativas em que as pessoas sugerem inversão na abordagem sobre a questão, por exemplo, a descriminalização e legalização das drogas.

Professora \#25: Eu acho que deveria ter um número dentro da universidade de denúncia anônima. Porque os colegas têm medo de falar qualquer coisa, medo de represálias de outros colegas, medo de falar que eu não tenho nada a ver com a vida desse aluno. Alguns colegas tem um certo receio. Então eu acho que se tivesse um número para denúncia anônima seria uma boa medida (Professora \#25, 57 anos, Jataí).

Professora \#13: Assinar o manifesto da liberação da maconha por exemplo. Eu acho que é isso, parar de hipocrisia. Temos que parar e enfrentar essa questão. $O$ problema não é o uso da droga. Mas a maneira que a sociedade utiliza essas questões. Eu não vejo, sou a favor da liberação das drogas. O que eu acho, que temos que discutir abertamente (Professora \#13, idade não identificada, Catalão).

Professor \#6: Olha, o consumo de drogas, ele sempre existiu, o problema é a guerra contra as drogas. A guerra às drogas mata mais que as drogas. A universidade tem de parar com esse discurso puritanista a respeito do consumo de drogas. As pessoas vão continuar a usar drogas. Porque tem gente que fuma um baseado para ficar mais relaxado e daí? [...] Então a universidade tem de largar esse discurso puritanista que tem lá fora, por que a universidade tem por dever, tratar as coisas de uma maneira mais racional, mais objetiva. Então o uso de drogas deveria ser uma conduta que não deveria 
ser criminalizada, não deveria ser crime. (Professora \#6, idade não identificada, Goiânia).

\section{c) Percepção sobre o Programa}

\section{Saudavelmente:}

A UFG dispõe de um programa denominado Saudavelmente com o objetivo de dar atenção à saúde mental de pessoas da comunidade universitária e também orientar e apoiar as que sejam usuárias de drogas. De acordo com Barreto (2007), o embrião da iniciativa se deu em 1988, quando assistentes sociais da Instituição passaram a perceber um grave absenteísmo entre servidores, provocado sobretudo pelo uso abusivo de álcool. De lá para cá, o programa não só ampliou seu público, pois envolve todos os segmentos da comunidade, como sua equipe, que hoje é multidisciplinar e conta com a participação de profissionais da área da psicologia, nutrição, psiquiatria, assistência social, arteterapia e enfermagem, além de voluntários. E também ampliou sua abrangência, uma vez que, além de oferecer terapia individual, familiar e coletiva, assim como grupos de autoajuda, musicoterapia, arteterapia, promove pesquisas, seminários e campanhas de conscientização além de articular redes com as famílias e serviços de atendimento externos à Universidade.

Entretanto, pela fala de uma servidora ligada ao programa, percebe-se que todo esse potencial está subutilizado, tanto por alunos quanto por servidores e professores, e isso pode ser explicado em virtude do estigma a que estão sujeitas as pessoas com transtornos mentais de um modo geral e, de maneira agravada, as que sofrem de dependência química.

O estudo de Barreto (2007) e a fala da servidora fazem crer que o álcool, mais que as drogas ilícitas, é responsável pela maior parte de transtornos da comunidade atendida. Disso se pode inferir que as questões psicofarmacológicas relativas às drogas ilícitas causam menos problemas e constrangimentos ao convívio da comunidade que o sentimento de insegurança provocado pela potencialidade de agregar práticas violentas, que são próprias do tráfico ilegal de drogas.

Entrevistador: Sobre o uso de drogas e tráfico de drogas na UFG. O que você pensa sobre o uso de drogas na comunidade universitária?

Técnica-administrativa \#7: $A h$, isso é um tema complicado. (risos). Eu acho que tem que... Eu sigo a mesma linha, acho que tem que se falar a respeito, tem que começar a discutir. É uma questão muito séria, muito séria! Muitos alunos estão sendo seriamente prejudicados, por causa do uso de drogas. De não conseguirem dar continuidade aos estudos, tudo começa muito bem, muito tranquilo, né! E aí as coisas vão se agravando.
Entrevistador: E quanto aos servidores? E professores?

Técnica-administrativa \#7: Ixi, também tem muitos, principalmente, tem essas drogas, mas o que eu acho mais grave é álcool.

Entrevistador: Muitos são dependentes?

Técnica-administrativa \#7: Muitos dependentes do álcool.

Entrevistador: Tem alguma medida específica [...] que a UFG poderia tomar em relação às drogas?

Técnica-administrativa \#7: Eu acho mesmo que tem a questão da responsabilização, né? De chamar a responsabilidade pra UFG. Porque... Agora criou o grupo, né... De estudos e pesquisas que eu acho que é um grande avanço. Mas durante muito tempo a UFG tratou isso, como... Não tem nada a ver com isso. Nós estamos aqui pra fornecer uma educação de qualidade. Essa questão de droga, festa, álcool os alunos discutem e conversam. Eles se entendem, eles têm autonomia pra isso. Só que eu acho que a gente tem que dar fundamentos pra que eles possam discutir. Então eu acho que a universidade tem que chamar a responsabilidade pra ela. Vamos sentar e discutir, né? Pelo menos as possíveis consequências. Pra dar... os fundamentos pra tomar as decisões. (Técnica-administrativa \#7, 30 anos, Goiânia).

\section{Grupo focal}

Conforme dito anteriormente, os grupos focais foram compostos exclusivamente por estudantes de graduação, de todos os câmpus e vinculados às mais diversas áreas de saber, o que torna impossível captar, por meio deles, a percepção de toda a comunidade sobre o uso e tráfico de drogas na UFG, já que foram excluídos os docentes, os/as técnico-administrativos e terceirizados/as. Ainda assim, pelas falas e informações captadas nos grupos focais, percebemos que existe uma forte proximidade entre os dados do survey e as entrevistas em profundidade.

As falas nos permitem trabalhar com dois focos: a associação entre tráfico e violência e o que chamam de desvirtuamento do ambiente acadêmico, que deveria ser "um lugar de estudo". Com relação ao primeiro tópico, "tráfico e violência", as falas denotam que o tráfico é responsável pela presença de armas de fogo nos câmpus, pela criação de um ambiente de insegurança. Assim, de acordo com uma das falas:

Eu já vi pessoas que não são alunos da Federal (UFG) traficando, já escutei pessoas que não são alunas que 
não são funcionárias, então entram lá somente pra vender maconha, crack ou qualquer outra coisa do tipo. Então a questão não é só a Federal ou o que a Reitoria pode fazer pra melhorar a segurança, o que que os alunos podem fazer, a questão é que existe um externo da Federal, existe um outro mundo, existem pessoas que nunca tiveram contato com aquilo dali que vão lá só pra fazer isso, então não resolve só melhorar, trancar, colocar muro, proibir a entrada de pessoas que são da comunidade que não é acadêmica isso não vai resolver nada. (Câmpus Colemar, Goiânia).

O tráfico, pelas falas, inevitavelmente está relacionado ao uso das armas de fogo. Trata-se do meio utilizado para realizar cobranças, acertos de contas e outros. Tal prática, contudo, também produz a sensação de insegurança.

Não tenho nada contra o traficante. Mas, penso que traz a violência, através deles estarem aqui chega outras pessoas pra resolver rixa com eles de problemas lá fora. Igual eu estava sentada na mesa a menina chegou procurando o cara. ${ }^{10}$ Não é expulsar eles daqui. Mas, agora a violência que chega aqui e as vezes que invadiram com arma e tudo foi entre eles, não foi nada contra alunos [...] Tem que descriminalizar isso. (Câmpus Samambaia, ${ }^{11}$ Goiânia).

Outra percepção diz respeito ao "desvirtuamento do ambiente acadêmico". Isto é, o espaço da Universidade já não é visto como um lugar seguro em que as pessoas buscam o crescimento intelectual por meio das aulas, da pesquisa e da leitura. Tem se tornado um ambiente marcado pela presença de pessoas "estranhas".

Eu não sei assim, porque a universidade é federal é um espaço público, mas eu acho que cada um tinha que respeitar o seu próprio limite, sem invadir o limite dos outros [...] Eu faço parte do grupo do $\mathrm{CA}^{\star 12}$ e ontem um colega chegou em mim pra reclamar comigo, que ele estava no CA fazendo o seminário dele e foi um homem oferecer drogas pra ele. Eu acho assim, cada pessoa tem o direito de usar, [...] Mas assim, deveria respeitar o seu limite, porque aqui é um espaço de estudo. [...]. Pra uma pessoa que nem sei se era estudante, chegar assim no aluno e oferecer drogas, eu não achei correto. (Câmpus Samambaia, Goiânia).
Tinha que ser proibido. Isso é uma instituição de educação, se o cara quer usar droga, vai usar droga lá na rua ou na casa dele. (Câmpus Goiás).

Algumas falas destoaram do grupo ao defender que a violência associada ao tráfico decorre do contexto da ilegalidade do comércio de drogas. Em consonância a essas falas surgiram também manifestações favoráveis à legalização, sobretudo da maconha. Também se destacou que embora haja traficantes externos à comunidade, foi dito que há estudantes e mesmo professores que vendem drogas ilícitas. Vejamos as falas:

Como é proibida a venda normalmente, então acaba criando um mercado negro. No caso da UFG, como aqui não tem polícia e não tem uma ronda muito forte, acaba que é mais tranquilo eles venderem e como tem muito consumidor, faz um capitalismo selvagem, daí vem muito traficante e ficam concorrendo. [...]. Se colocar a polícia e outro tipo de coisa vai acabar com o consumo aqui dentro e acabar com os traficantes é errôneo, porque os próprios estudantes que vendem, até já ouvi falar que professor vende essas coisas isso não vai acabar com o tráfico de drogas. (Câmpus Samambaia, Goiânia).

Aqui também tem, né? Na praça (Praça Universitária) tem muito tráfico. E eu acho que atrai também, por isso que eu sou a favor da legalização, não sou contra o uso, sou contra o tráfico por várias questões. (Câmpus Colemar, Goiânia).

Outro questionamento que podemos destacar nas falas diz respeito à abordagem da gestão sobre o tema. Algumas falas destacaram que a UFG não debate sobre drogas, e que em alguns câmpus acabam reproduzindo a mesma política repressiva, em vez de criar outras formas de tratar o assunto.

Eu acredito que a UFG seja um recorte de tudo que tem fora dela, é um recorte do mundo que tá aqui, sabe, então não tem como você separar a violência que tem lá dentro da violência que tem aqui fora, que uma coisa é um reflexo da outra, né. (Câmpus Colemar, Goiânia).

Igual, não tem, mas não custa fazer seminários pra prevenir. Não é porque não tem que a gente pode deixar, mas tem que ter aquela prevenção. Igual a

10. Refere-se a um episódio em que uma suposta traficante foi armada a um evento anual, denominado Espaço das Profissões que tem o intuito de apresentar a UFG e seus cursos de graduação a estudantes do ensino médio.

11. O Câmpus Samambaia fica mais afastado da região central e o Câmpus Colemar Natal e Silva está localizado em área mais central, na Praça Universitária e seus arredores, região em que também se situa a PUC/GO.

12. De acordo com o levantamento. 
questão da violência, não tem a violência, mas vamos fazer seminários pra continuar não tendo, né. Vamos prevenir aquilo. (Câmpus Goiás).

Embora possamos assumir, pelo conjunto das falas, que a percepção do tráfico de drogas ilegais no âmbito da universidade afeta negativamente o sentimento de segurança de sua comunidade, há dados provenientes da pesquisa enfocada, cujos resultados não cabem ser aqui discutidos, que evidenciam que a Universidade, embora seja um "recorte" do mundo que a cerca, tem índices de crimes, de um modo geral, muito significativamente mais baixos do que os praticados na cidade de Goiânia, que é considerada uma das cidades mais violentas do país. O mesmo se pode dizer com relação aos demais câmpus, situados fora da capital.

\section{Incidência do consumo}

\section{Survey}

O Survey, mais abrangente que os grupos focais, por englobar toda a comunidade universitária e incluir os servidores terceirizados, questionou se o/a respondente havia experimentado droga ilícita e, referente aos/às estudantes, sobre qual ou quais drogas, entre lícitas e ilícitas já haviam experimentado e, em caso afirmativo, se antes ou depois de ingressar na Instituição e se nas dependências da UFG. É importante fazer uma ressalva quanto ao fato de que a ilegalidade de determinadas drogas pode inibir uma resposta afirmativa de seu uso, bem como é interessante perceber, conforme Tabela 5, que o percentual mais alto de pessoas que experimentaram está na categoria técnico-administrativos (servidores de carreira), seguida pela categoria professores, e só então pela categoria alunos, que supera a terceirizados. Não há, para todas as categorias de entrevistados/as a menção a qual ou quais drogas essas pessoas experimentaram, o que foi feito somente entre estudantes e englobando drogas lícitas e ilícitas. O resultado aponta para a prevalência de uso de álcool, seguido por tabaco, maconha e haxixe (ambas em uma mesma questão, sem diferenciação), tranquilizantes e ansiolíticos, Ecstasy e LSD. ${ }^{13}$

\section{Discussão}

Assim como é problemática a definição acerca da nocividade ou pertinência de substâncias psicoativas - desde aquelas satanizadas até as toleradas (como psicotrópicos) -, também é problemática a definição do que seja o uso abusivo dessas substâncias. Desde fatores individuais, como os biológicos e ou psicológicos, até fatores ambientais, como os socioculturais, tendem a influenciar se, para determinado indivíduo, o uso de substância psicoativa é abusivo e nocivo. A Organização Mundial da Saúde (OMS) traça parâmetros por meio dos quais se define o diagnóstico de dependência, ${ }^{14}$ e esses critérios passam pela avaliação dos danos físicos, psíquicos e sociais que o uso da substância impõe ao indivíduo. Relatório expedido pela OMS (2004) menciona dados de 2002, acerca da

carga global das doenças, que atribuem ao consumo de drogas psicoativas $8,9 \%$ dessa carga. Em dados de 2000 , essa carga de $8,9 \%$ é distribuída em 4,1\% para o tabaco e $4 \%$ para o álcool, restando apenas $0,8 \%$ para todas as drogas consideradas ilícitas.

As entrevistas em profundidade nos levaram a perceber a incidência de consumo de álcool, entorpecentes e de psicotrópicos não só entre os estudantes da universidade, mas, também, entre professores e técnico-administrativos. O uso de álcool se dá, por exemplo, nas imediações da UFG, em todas as suas regionais, sobretudo em bares da região. Em Goiânia, particularmente, o consumo de maconha e de outros entorpecentes ocorre no Bosque Auguste de Saint-Hilaire, ${ }^{15}$ no interior de alguns Centros Acadêmicos

\footnotetext{
13. De acordo com o levantamento.
}

14. Classificação F19 no CID 10 - Transtornos mentais e comportamentais decorrentes do uso de múltiplas drogas e do uso de outras substâncias psicoativas - Critérios de dependência de substâncias segundo a CID-10. Presença de três ou mais dos seguintes sintomas em qualquer momento durante o ano anterior: 1) desejo forte ou compulsivo para consumir a substância; 2) dificuldades para controlar o comportamento de consumo de substância em termos de início, fim ou níveis de consumo; 3) estado de abstinência fisiológica quando o consumo é suspenso ou reduzido, evidenciado por: síndrome de abstinência característica, ou consumo da mesma substância (ou outra muito semelhante) com a intenção de aliviar ou evitar sintomas de abstinência; 4) evidência de tolerância, segundo a qual há a necessidade de doses crescentes da substância psicoativa para se obter os efeitos anteriormente produzidos com doses inferiores; 5) abandono progressivo de outros prazeres ou interesses em razão do consumo de substâncias psicoativas, aumento do tempo empregado em conseguir ou consumir a substância, ou recuperar-se dos seus efeitos; 6) persistência no consumo de substância apesar de provas evidentes de consequências manifestamente prejudiciais, tais como lesões hepáticas causadas por consumo excessivo de álcool, humor deprimido consequente a um grande consumo de substância, ou perturbação das funções cognitivas relacionada com a substância. Devem fazer-se esforços para determinar se o consumidor estava realmente, ou poderia estar, consciente da natureza e da gravidade do dano.

15. Uma das poucas áreas com a vegetação primitiva do município de Goiânia, o Bosque Auguste de Saint-Hilaire encontra-se localizado no Campus II da UFG (Câmpus Samambaia). Com área de aproximadamente 20 hectares, e um remanescente da formação vegetal, floresta semidecídua do bioma Cerrado, ocorrente no estado de Goiás. Fonte: <https://www.uc.ufg.br/n/29384-bosque-s-hilarie>. 
(CA), do Diretório Central dos Estudantes (DCE), e nas Casas do Estudante Universitário (CEU), por exemplo.

No caso específico do Câmpus Samambaia, ${ }^{16}$ nota-se nos depoimentos uma percepção sobre o aumento da venda de drogas dentro da própria UFG, exercido por traficantes oriundos de bairros próximos a esse Câmpus - como o bairro Itatiaia - os quais não fazem parte da comunidade universitária.

Opiniões divergem quanto ao uso, pois há os que afirmam que a universidade é um espaço em que o uso de drogas ilícitas é "natural", mas ressalvam que esse uso deve ser debatido e/ou controlado de alguma maneira pela UFG. Enquanto outros consideram que esse consumo deve ser totalmente proibido no âmbito da instituição. Dentre os entrevistados, há os que entendem que, assim como a sociedade em geral, a própria UFG marginaliza seus alunos usuários de entorpecentes, e consideram haver oferta insuficiente de assistência social a estudantes dependentes pela instituição. Essa percepção deve ser relativizada, pois não foram dados exemplos quanto a atitudes discriminatórias por parte da instituição. Quanto à alegada ineficiência de oferta de auxílio, talvez possa se explicar por dados contidos na Tabela 6, que evidenciam o desconhecimento, por parte da comunidade, de programas que tratem da questão das drogas no âmbito da Universidade. Ademais, não fica claro se as pessoas que fazem uso recreativo de drogas, ou mesmo as que possam ser classificadas como dependentes estejam dispostas a buscar algum tipo de ajuda na instituição, embora seja inegável a importância dessa oferta.

\section{Conclusão}

O uso de substâncias psicoativas acompanha a história da humanidade. As representações acerca dos usos e das substâncias propriamente ditas têm variado de acordo com o tempo e a cultura e são influenciadas por vieses interseccionais de raça, classe e gênero. Esses vieses irão influenciar em que campo a discussão irá se situar, se no campo criminal ou da saúde pública (Linnemann; Siqueira; Westfall, 2008).
A disputa entre campos de saberes tem se refletido no âmbito das universidades, tanto com relação à produção de conhecimento quanto às políticas que devem adotar a respeito do uso por membros de sua própria comunidade. Sobretudo nos últimos trinta anos, em que aumentou significativamente o consumo e tráfico de drogas ilícitas no Brasil, esforços têm sido empreendidos no sentido de avaliar a conveniência de políticas adotadas com base em, predominantemente, três paradigmas: o proibicionista; o que defende a legalização e controle visando à redução de danos; e o que defende a avaliação de acordo com o tipo da droga, e rígido controle social sobre elas, conforme tem acontecido com relação às leis que visam a dificultar o uso do tabaco, substância lícita (Laranjeira, 2010).

A reflexão sobre políticas de drogas, seja no âmbito da Universidade, seja na sociedade ampliada, deve levar em conta que: a) dados trazidos pela OMS acerca da carga global de doença apontam maior relevância para as drogas lícitas que as ilícitas; b) as políticas públicas de saúde e de segurança têm reforçado desigualdades sociais, ao se distinguirem de acordo com o perfil social, tanto de usuários/as quanto de traficantes, como se vê, por exemplo, no caso do Ecstasy e do Crack; c) a falta de evidências de que efeitos psicofarmacológicos da droga ilícita mais usada no mundo, a maconha, possam gerar comportamentos violentos. São elementos que levam a crer que a discussão é muito mais pautada por parâmetros morais enviesados por questões de classe do que por evidências fundadas em pesquisas no campo da saúde, das ciências sociais - sociologia, economia, antropologia. Tais pesquisas muito poderiam auxiliar para que fossem considerados caminhos capazes de enfrentar o fato de que é ilusório o pleito por uma sociedade sem drogas, pois a própria história da humanidade nega essa possibilidade e, diante da realidade inexorável, mitigar os efeitos colaterais advindos do abuso de substâncias psicoativas que, indubitavelmente, são menos nefastos que as violências geradas pelo tráfico ilegal de drogas. A Universidade tem, portanto, um papel crucial a desenvolver nesse problema.

\section{Referências}

ASCHIDAMINI, I. M.; SAUPE, R. Grupo focal, estratégia metodológica qualitativa: um ensaio teórico. Cogitare Enfermagem, Curitiba, v. 9, n. 1, p. 9-14, 2004.

BARRETO, Ivete Santos. Programa de atenção à saúde mental dos trabalhadores das Instituições Federais de Ensino
Superior. 2007. Dissertação (Mestrado em Ciências da Saúde) - UNB, Brasília, 2007.

BERNARD, H. Russel. Research methods in Cultural Anthropology. London, New Delhi: Sage, 1988.

BORGES, Camila Delatorre; SANTOS, Manoel Antônio

16. A Regional Goiânia tem dois Câmpus, um deles mais central e o outro, denominado Samambaia, em uma região mais afastada do Centro, onde se situa o referido Bosque Saint-Hillaire. 
dos. Aplicações da técnica do grupo focal: fundamentos metodológicos, potencialidades e limites. Rev. SPAGESP, Ribeirão Preto, v. 6, n. 1, p. 74-80, jun. 2005.

BUCHER, Richard; OLIVEIRA, Sandra R. M. O discurso do "combate às drogas" e suas ideologias. Rev. Saúde Pública, São Paulo, v. 28, n. 2, p. 137-145, abr. 1994. BRASIL. Presidência da República. Secretaria Nacional de Políticas sobre Drogas. I Levantamento nacional sobre o uso de álcool, tabaco e outras drogas entre universitários das 27 capitais brasileiras. Secretaria Nacional de Políticas sobre Drogas; GREA/IPQ-HC/FMUSP; organizadores Arthur Guerra de Andrade, Paulina do Carmo Arruda Vieira Duarte, Lúcio Garcia de Oliveira. Brasília: Senad, 2010.

CARNEIRO, Henrique. 2002. A fabricação do vício. Disponível em: <http://www.neip.info/index.php/ content/view/2469.html>. Acesso em: 15 ago. 2016.

CEBRID - Centro Brasileiro de Informação sobre Drogas Psicotrópicas. II Levantamento domiciliar sobre o uso de drogas psicotrópicas no Brasil: estudo envolvendo as 108 maiores cidades do país: 2005. CARLINI, E. A. (Superv.) et al. São Paulo: Cebrid: Unifesp - Universidade Federal de São Paulo, 2006.

CENTER for Behavioral Health Statistics and Quality. Behavioral health trends in the United States: results from the 2014 national survey on drug use and health. HHS Publication, n. SMA 15-4927, NSDUH Series H-50, Sept. 2015. Disponível em: <https://www.samhsa.gov/ data/sites/default/files/NSDUH-FRR1-2014/NSDUHFRR1-2014.pdf>. Acesso em: 9 fev. 2017.

COYLE, Michael. Race and Class Penalties in Crack Cocaine Sentencing. ANNUAL MEETING OF THE AMERICAN SOCIOLOGICAL ASSOCIATION, Atlanta Hilton Hotel, Atlanta, GA, Aug. 16, 2003.

CRUZ, Olga Souza; MACHADO, Carla; FERNANDES, Luís. O 'problema da droga': sua construção, desconstrução e reconstrução. Lisboa: Aná. Psicológica, v. 30, n. 1-2, p. 49-61, jan. 2012.

FIORE, Maurício. O lugar do Estado na questão das drogas: o paradigma proibicionista e as alternativas. Novos Estudos - CEBR AP, São Paulo, n. 92, p. 9-21, mar. 2012. GIRARD, René. O bode expiatório. São Paulo: Editora Paulus, 2004.

GIRARD, René. A violência e o sagrado. São Paulo: Editora Paz e Terra, 2008.

GOLDSTEIN, Paul. J. The drugs/violence nexus: a tripartite conceptual framework, Journal of Drug Issues, v. 15, p. 493-506, 1985.

LARANJEIRA, Ronaldo. Legalização de drogas e a saúde pública. Rio de Janeiro: Ciênc. Saúde Coletiva, v. 15, n. 3, p. 621-631, May 2010 .

LEMGRUBER, Julita; BOITEAUX, Luciana. O fracasso da Guerra às drogas In: LIMA, R. S.; RATTON, J. L.; AZEVEDO, R. G. de. Crime, polícia e justiça no Brasil. São Paulo: Editora Contexto, 2014.

LINNEMANN, T. W.; SIQUEIRA, A.; WESTFALL, D. "Mad Men, Meth Moms, and Moral Panic: Gendering Meth Crimes in the Midwest". ANNUAL MEETING OF THE ASC ANNUAL MEETING, St. Louis Adam's Mark, St. Louis, Missouri. Nov. 2008.

MACHADO, L. V.; BOARINI, M. L. Políticas sobre drogas no Brasil: a estratégia de redução de danos. Psicologia: Ciência e Profissão, v. 33, n. 3, p. 580-595, 2013. MINAYO, Maria Cecília. de S. O desafio do conhecimento. 11. ed. São Paulo: Editora Hucitec, 2008.

MINAYO, Maria Cecília de Souza; DESLANDES, Suely Ferreira. A complexidade das relações entre drogas, álcool e violência. Rio de Janeiro: Cad. Saúde Pública, v. 14, n. 1, p. 35-42, jan. 1998.

OMS - Organização Mundial de Saúde. Neurociência de consumo e dependência a substâncias psicoativas. Genebra: WHO Library, 2004.

PELEGRINI, Marta Regueira Fonseca. O abuso de medicamentos psicotrópicos na contemporaneidade. Psicol. Cienc. Prof., Brasília, v. 23, n. 1, p. 38-41, mar. 2003. ROE B.; BEYNON C.; PICKERING L.; DUFFY P. Experiences of drug use and ageing: health, quality of life, relationship and service implications. Journal of Advanced Nursing, v. 66, n. 9, p. 1968-1979, 2010.

SENADO FEDERAL. Drogas. Brasília: Senado Federal, Coordenação de Edições Técnicas, 2015.

SHECAIRA, Sérgio Salomão. Drogas e criminologia. In: LIMA, R. S.; RATTON, J. L.; AZEVEDO, R. G. de. Crime, polícia e justiça no Brasil. São Paulo: Editora Contexto, 2014.

TAYLOR, Matthew H.; GROSSBERG, George T. The growing problem of illicit substance abuse in the elderly: a review. The Primary Care Companion for CNS Disorders. v. 14, n. 4, 2012.

TORCATO, Carlos Eduardo Martins. A história das drogas e sua proibição no Brasil: da Colônia à República. 2016. Tese (Doutorado em História Social) - Departamento de História. Universidade de São Paulo, São Paulo, 2016.

TRAD, Leny A. Bomfim. Grupos focais: conceitos, procedimentos e reflexões baseadas em experiências com o uso da técnica em pesquisas de saúde. Physis, Rio de Janeiro, v. 19, n. 3, p. 777-796, 2009.

ZALUAR, Alba Maria. Drogas: um panorama no Brasil e no mundo. Ciência Hoje, v. 181, p. 5, 2002. 


\title{
Incidence and representations of the use of licit and illicit drugs in campuses at the Federal University of Goiás: challenges for proposing a policy
}

\begin{abstract}
Legal and illegal drugs consumption in universities has been tracked in Brazil and in many other countries and has challenged these institutions to reflect on the execution of policies that won't reproduce the mistakes faced by most of the current initiatives in more broadly public sphere. This paper aims to analyze the currency and perceptions of legal and illegal drugs use in the campus of the Federal University of Goiás (UFG), from data collected in the years of 2015 and 2016 by three procedures: survey, focus groups and in-depth interviews, starting from this analysis, we hope to contribute on the reflection about the policies that may reduce the damage that drug consumption and people's perception of it can potentially cause in the Institutions' Academia communities, which includes bringing to discussion in what levels prenotion against drugs, especially the illegal ones, as well as the use of these substances can affect the quality of community life.
\end{abstract}

Keywords: psychoactive substances, universities, drugs policies.

\section{Incidencia y representaciones del uso de drogas lícitas e ilícitas en el campus de la Universidad Federal de Goiás: desafíos para proponer una política}

\section{Resumen}

El uso de sustancias psicoactivas lícitas e ilícitas en las universidades ha sido mapeado en Brasil, como en otros países, y ha desafiado a estas instituciones a reflexionar sobre la implementación de políticas que no reproduzcan los errores de la mayoría de las iniciativas existentes en las esferas públicas mayores. El objetivo de este trabajo es analizar la incidencia y las percepciones del uso de drogas lícitas e ilícitas en los campos de la Universidad Federal de Goiás (UFG), a partir de los datos recogidos en los años 2015 y 2016 a través de tres procedimientos: encuesta, grupos focales y entrevistas en profundidad y, desde este análisis, vamos a tratar de contribuir a la reflexión sobre las políticas que puedan reducir los daños que tanto la percepción del consumo como el propio consumo real de estas sustancias potencialmente pueden causar a las comunidades de las instituciones de educación superior, incluyendo la discusión sobre en qué medida los pre-nociones relacionadas a las drogas, sobre todo las ilícitas, así como el uso de estas sustancias pueden afectar a la calidad de la convivencia en esa comunidad.

Palabras clave: sustancias psicoactivas, universidades, política de drogas.

Data de recebimento do artigo: 05/ 2016 Data de aprovação do artigo: 11/2016 